\title{
A Study of the Collaborative Degree between Economic Growth and Carbon Reduction Targets under International Comparative Perspective
}

\author{
Liang Qu, Cong Chen, Wulin Zhang \\ School of Business Administration, Zhejiang Gongshang University, Hang Zhou, 310018, China
}

\begin{abstract}
This paper figures out the collaborative degree between economic growth and carbon reduction targets of China, India, the Netherlands, the United Kingdom, the United States and Japan with relevant energy consumption data, carbon emissions data and related economic development data from 1981 to 2010 by constructing economic growth and carbon reduction targets complex systems collaborative degree model. Based on international comparative research framework, this research made the international comparison from a line through the point perspective. And the result is shown in the conclusion part.
\end{abstract}

Keywords-carbon reduction; economic growth; collaborative degree; international comparison.

\section{INTRODUCTION}

During the Warsaw Conference on climate change in 2013, the enthusiasm of developed countries on carbon reduction was generally reduced. Since the internal division and the debt crisis, the European Union put forward the first commitment period of the appraisal report until 2016. The U.S. Congress is disunited to stop the climate change legislation. Canada excused that unable to pay the emission fine and out of the "Kyoto Protocol". Besides, Japan abandoned a $25 \%$ reduction target due to the nuclear accident. Furthermore, the rapid economic development in Brazil, India and China and other emerging markets has dramatically changed their reduction ability, potential and economic strength in the internal negotiating parties. The developed countries gradually transferred their focus from the climate change diplomacy to developing countries. Although the urgency of climate change has been well recognized by the world, the key problems such as carbon emission, reduction responsibility division, labor division and climate change assistance funding have not reached a worldwide consensus yet. All of the countries are not certain that whether the conflict exists between developing low carbon economy and accelerating economic growth is becoming the important reason that hinder the global consensus.

Based on the perspective of international comparison, this paper tries to construct the collaborative degree model of economic growth and carbon emission reduction targets composite system, and estimate the degree of synergy of six countries by collecting the energy consumption data, carbon emissions data and economic development data from 1981 to 2010 issued by the world bank of China, India, Holland, the UK and Japan, America. Then clear the gap of low carbon economy between china and some major developed countries by comparing, and explore the causes of the gap and put forward a realistic way to narrow the gap. This paper mainly includes: (1) Pointing out the deficiencies of the existing international comparative research framework, and improving the analytical framework of the international comparative study on low-carbon economy construction. (2) Constructing the collaborative degree model of economic growth and carbon emission reduction targets composite system. (3) Clarifying the gaps between different countries and explore its causes and finally putting forward the realistic way to narrow the gap based on the coordination of the empirical results.

\section{CONSTRUCTION OF INTERNATIONAL COMPARATIVE RESEARCH METHODS BASED ON THE SYSTEM PERSPECTIVE}

This paper aims to put forward a system opinion based on international comparative research, which reveals the general historical development through multi comparison, as well as realizes the growth difference in different countries, by international comparison. So that we can calculate the time of narrowing the gap and conclude relatively comprehensive and systematic international comparison results by analyzing the typical year's event and summarizing the mechanism behind producing and narrowing the national gap. Therefore, this paper divided the international comparative research framework of economic growth and carbon reduction target composite system collaborative degree into three parts, which makes the comparison from a line through the point perspective: (1) Posing problems. Based on analysis and comparison in a long-term series, this paper aims to summarize a general rule, put forward questions, and clarify the reality gap. (2) Analyzing the problem. Summarize the growth potential and ensure the possible time that could narrow the gap. (3) Solving the problem. Reveal the internal factors of economic and social development of all countries based on the analysis of years that is crucial for the research.

\section{MODEL, INDEX AND DATA}

\section{A. Subsystem order degree model}

For subsystem $F_{i}, \quad i \in[1, n]$, let order parameter be the $e_{j}=\left(e_{j 1}, e_{j 2}, \ldots, e_{j n}\right)$ in its development process, which $\mathrm{n} \geq 1, \quad \beta_{j i} \leq e_{j i} \leq \alpha_{j i}, i=1,2, \cdots, n, \alpha_{j i}, \beta_{j i}$ is the 
upper limit and lower limit of the order parameter $e_{j i}$. According to the order parameter principle and slaving principle of Synergetics, three efficiency coefficients, positive efficiency coefficient, negative efficiency coefficient and moderate efficiency coefficient exist in subsystem.

If the contribution to the order parameter of the system order degree increases along with the order parameter variable, we can call it positive efficiency coefficient, which can be written as follows:

$$
U_{j}\left(e_{j i}\right)=\frac{e_{j i}-\beta_{j i}}{\alpha_{j i}-\beta_{j i}}
$$

Where, the positive efficiency coefficient $U_{j}\left(e_{j i}\right) \in[0,1]$. When the subsystem order parameter variable is the maximum value of $\alpha_{j i}$, the subsystem contributes to the order degree of the system for a maximum of 1 . When the order parameter variable comes to the minimum value, the contribution to the order degree of the system would be the minimum value of 0 .

If the contribution to the order parameter of the system order degree decreases with the increase of the order parameter variable, we can call it negative efficiency coefficient, which can be written as follows:

$$
U_{j}\left(e_{j i}\right)=\frac{\alpha_{j i}-e_{j i}}{\alpha_{j i}-\beta_{j i}}
$$

Where, the negative efficiency coefficient $U_{j}\left(e_{j i}\right) \in[0,1]$. When the subsystem order parameter variable is the maximum value of $\alpha_{j i}$, the subsystem contributes to the order degree of the system for a minimum of 0 . When the order parameter variable comes to the minimum value, the contribution to the order degree of the system would be the maximum value of 1 .

If the order parameter variable takes a value between $\alpha_{j i}$ and $\beta_{j i}$, the contribution of subsystem to the system order degree would be the maximum, which can be called the moderate efficiency coefficient. The expression can be written as follows:

$$
U_{j}\left(e_{j i}\right)=\frac{\alpha_{j i}-e_{j i}}{\alpha_{j i}-\gamma_{j i}}
$$

Or

$$
U_{j}\left(e_{j i}\right)=\frac{\alpha_{j i}-e_{j i}}{\gamma_{j i}-\beta_{j i}}
$$

Where, $\beta_{j i} \leq \gamma_{j i} \leq \alpha_{j i}, U_{j}\left(e_{j i}\right) \in[0,1]$. When the subsystem order parameter variable takes a value of $\gamma_{j i}$, the contribution value to the system order degree would be the maximum of 1 .

On the basis of efficacy coefficient, we can calculate the contribution value of subsystem to the order degree target system. Linear weighting method and the geometric mean method would be the general method to help to calculate the contribution value. As the result, the subsystem order degree can be expressed by word I as follows:

$$
\mathrm{I}_{j}\left(e_{j}\right)=\sum_{i=1}^{n} \omega_{i} U_{j}\left(e_{j i}\right)
$$

Or

$$
I_{j}\left(e_{j}\right)=\sqrt[i]{\prod_{i=1}^{n} U_{j}\left(e_{j i}\right)}
$$

Where, $\omega_{i} \geq 0$ is the weight coefficient of the index, $\sum_{i=1}^{n} \omega_{i}=1, I_{j} \in[0,1] . \mathrm{I}_{\mathrm{j}}$ is for the subsystem order degree, the larger the value, the higher the order degree of the subsystem. This paper calculates the subsystem order degree with the linear weighting method.

\section{B. Complex system collaborative degree model}

Assume in the given initial time of $\mathrm{t}_{0}$, the order degree of carbon reduction targets subsystem $\mathrm{F}_{1}$ is $I_{1}^{0}\left(e_{1}\right)$, the order degree of economic growth target subsystem F2 is $I_{2}^{0}\left(e_{2}\right)$; In another moment $t_{2}$ in the process of development and evolution in the composite system, assume that the order degree of subsystem $\mathrm{F}_{1}$ is $I_{1}^{1}\left(e_{1}\right)$ and the order degree of subsystem F2 is $I_{2}^{1}\left(e_{2}\right)$. The formula below represents the cooperative degree of economic growth target of composite system.

$$
\mathrm{C}=\operatorname{sig}(\cdot) \times \sqrt{\left|I_{1}^{1}\left(e_{1}\right)-I_{1}^{0}\left(e_{1}\right)\right| \times\left|I_{2}^{1}\left(e_{2}\right)-I_{2}^{0}\left(e_{2}\right)\right|}
$$

Where,

$\operatorname{sig}(\cdot)=\left\{\begin{array}{l}1, I_{1}^{1}\left(e_{1}\right)-I_{1}^{0}\left(e_{1}\right) \geq 0, I_{2}^{1}\left(e_{2}\right)-I_{2}^{0}\left(e_{2}\right) \geq 0 \\ -1, \text { others }\end{array}\right.$

The formula indicates that the carbon reduction goals and economic growth target composite system can be calculated by based on the dynamic analysis of time series. $C \in[-1,1]$, and it indicates that the greater the value, the higher of the cooperative degree.

\section{Index selection and data collection}

This paper chooses the energy intensity, the proportion of non-fossil energy, the growth rate of per capital carbon dioxide emissions to measure the order degree of carbon emission reduction system; besides, this paper selects the GDP growth, per capital GDP growth and the proportion of the third industry. This research collects the data of economic growth, carbon emissions and energy consumption from 1981 to 2010 of India, China, UK, the Netherlands, US and Japan through the World Bank website. Firstly, we preprocess the data due to the different units of measurement data. For forward effectiveness index, the data should be normalized with the formula one, for negative effectiveness index, the data should be normalized by the formula two. For carbon reduction subsystem, the energy intensity and the growth rate of per capital carbon dioxide emissions are negative effectiveness index, and the proportion of non-fossil energy is forward effectiveness index; but the three indicators above are all positive effectiveness coefficient for economic growth subsystem.

After normalization treatment, this paper applies the CRITIC objective weighting method for empowerment evaluation of each indicator. The weight of evaluation index is determined by two factors: standard deviation and correlation, which are the basic content of CRITIC. 
Standard deviation reflects the variability of evaluation index. The higher the degree of variation is, the greater the standard deviation is. The correlation coefficient indicates that the influence of one variable to other variable. More specific information is shown as follows:

$$
C_{j}=\sigma_{j} \sum_{i=1}^{n}\left(1-r_{i j}\right), \mathrm{j}=1, \ldots, \mathrm{n}
$$

Where, $r_{i j}$ is the correlation coefficient between the evaluation index $\mathrm{i}$ and $\mathrm{j}$. $\sigma_{j}$ represents the standard deviation of the index $\mathrm{j} . \mathrm{C}_{\mathrm{j}}$ indicates all the information of index $\mathrm{j}$. The more important index $\mathrm{j}$ is, the larger the value is. So the weight of index $\mathrm{j}$ is as the following formula:

$$
\omega_{j}=\frac{{ }^{c_{j}}}{\sum_{{ }_{1}{ }^{n}{ }{ }_{j}}}, \mathrm{j}=1, \ldots, \mathrm{n}
$$

We can get all the index coefficient of all the countries measured this time according to the formula (9). The results are shown in the table 1 as follows. Besides, subsystem order degree and subsystem coordination degree can be derived from the formula (5), which is calculated with the weight of each index and efficiency coefficient. Furthermore, the collaborative of composite system can be drawn from the formula (7).

\begin{tabular}{|c|c|c|c|c|c|c|}
\hline & UK & NLD & US & JPN & $\mathrm{CHN}$ & IND \\
\hline GDP Growth & 0.2084 & 0.2009 & 0.2103 & 0.1992 & 0.2427 & 0.2361 \\
\hline Per Capital GDP Growth & 0.2173 & 0.2020 & 0.2093 & 0.1906 & 0.2140 & 0.1952 \\
\hline Tertiary Industry Proportion & 0.5743 & 0.5970 & 0.5804 & 0.6102 & 0.5433 & 0.5687 \\
\hline Energy intensity & 0.3704 & 0.4567 & 0.2689 & 0.3128 & 0.3147 & 0.4091 \\
\hline Per Capital CO2 Growth & 0.2804 & 0.2748 & 0.4641 & 0.3642 & 0.3678 & 0.3655 \\
\hline The proportion of non-fossil energy & 0.3492 & 0.2685 & 0.2670 & 0.3230 & 0.3176 & 0.2253 \\
\hline
\end{tabular}

TABLE I. THE RESULTS OF EACH INDEX WEIGHT OF EACH COUNTRY

\section{EMPIRICAL RESULT}

We can get the order degree of economic subsystem (referred to as economic order degree), the order degree of carbon emission reduction system (referred to as carbon order degree), economic subsystem coordination degree (referred to as the economic collaborative degree), carbon emission reduction subsystem coordination degree (referred to as carbon collaborative degree) and composite system coordination degree (referred to as complex collaborative degree)of six countries based on the models and data from the previous chapter. The following Table 2 shows the result of China in 20 years.

\begin{tabular}{|c|c|c|c|c|c|}
\hline Years & $\begin{array}{c}\text { complex collaborative } \\
\text { degree }\end{array}$ & $\begin{array}{c}\text { Economic collaborative } \\
\text { degree }\end{array}$ & $\begin{array}{c}\text { Carbon collaborative } \\
\text { degree }\end{array}$ & $\begin{array}{c}\text { Economic order } \\
\text { degree }\end{array}$ & $\begin{array}{c}\text { Carbon order } \\
\text { degree }\end{array}$ \\
\hline 2002 & -0.0426 & 0.0585 & -0.0310 & 0.7209 & 0.6859 \\
\hline 2003 & -0.0838 & 0.0310 & -0.2266 & 0.7519 & 0.4593 \\
\hline 2004 & -0.0401 & -0.0169 & 0.0954 & 0.7351 & 0.5547 \\
\hline 2005 & 0.0772 & 0.0513 & 0.1161 & 0.7864 & 0.6708 \\
\hline 2006 & -0.0251 & 0.0673 & -0.0094 & 0.8537 & 0.6614 \\
\hline 2007 & 0.0939 & 0.0847 & 0.1041 & 0.9384 & 0.7655 \\
\hline 2008 & -0.1337 & -0.1853 & 0.0965 & 0.7530 & 0.8619 \\
\hline 2009 & -0.0436 & 0.0247 & -0.0768 & 0.7777 & 0.7851 \\
\hline 2010 & 0.0465 & 0.0468 & 0.0461 & 0.8246 & 0.8313 \\
\hline
\end{tabular}

TABLE II. THE RESULT OF CHINA FROM 1981-2010

\section{A. Overall comparison based on time series}

This section mainly compares six countries between the system order degree and collaborative degree. Order degree represents the coordinated degree of all the elements among the system. The more reasonable the internal structure of system is, the higher the order degree is. This paper calculates the order degree of both economic growth subsystem and carbon emission reduction subsystem, as well as the related mean of collaborative system of six countries from $1981-2010$ as table 3 and table 4 below. 
TABLE III. DESCRIPTIVE STATISTICS OF SUBSYSTEM ORDER DEGREE OF SIX COUNTRIES

\begin{tabular}{ccccc}
\hline & \multicolumn{2}{c}{ Economic growth order degree } & \multicolumn{2}{c}{ Carbon reduction order degree } \\
\hline NLD & Mean & SD & Mean & .1434549 \\
UK & .634097 & .2190628 & .554490 & .512470 \\
US & .597890 & .1948584 & .531290 & .1863996 \\
JPN & .575923 & .1613475 & .549537 & .1524060 \\
IND & .522340 & .1609674 & .505430 & .1954049 \\
CHN & .524203 & .2507749 & .522670 & .1919853 \\
\hline
\end{tabular}

TABLE IV. DESCRIPTIVE STATISTICS OF THE COORDINATED DEGREE OF SIX COUNTRIES

\begin{tabular}{|c|c|c|c|c|c|c|}
\hline & \multicolumn{2}{|c|}{$\begin{array}{c}\text { Collaborative degree of Economic } \\
\text { growth }\end{array}$} & \multicolumn{2}{|c|}{ Collaborative degree of carbon reduction } & \multicolumn{2}{|c|}{ Collaborative degree of composite system } \\
\hline & Mean & SD & Mean & SD & Mean & SD \\
\hline NLD & .024303 & .0880252 & .009420 & .1078171 & -.016923 & .0833992 \\
\hline UK & .023671 & .0936625 & .014679 & .1128423 & -.016817 & .0890679 \\
\hline US & .019554 & .0949951 & .008401 & .1508323 & -.060385 & .0826180 \\
\hline JPN & .019835 & .0698104 & .011954 & .1516018 & -.034096 & .0898836 \\
\hline IDN & .027115 & .1198022 & .022017 & .1411850 & -.023941 & .1048481 \\
\hline CHN & .026248 & .1157401 & .017292 & .0785508 & -.026281 & .0674045 \\
\hline
\end{tabular}

According to the table 3, Holland and UK have the highest mean value of economic order degree from 1981-2010, and followed by China and the US, while India and Japan have the lowest mean value. Although there is no significant difference, the economic order degree of developed countries is higher than developing countries in general.

From the economic growth subsystem collaborative degree aspect, India and China have the highest mean value of economic collaborative degree from 1982-2010, and followed by UK and Holland, while US and Japan have the lowest mean value. Under the background of global economic integration, China and India and such developing countries become the workshop of the world, with the rapid development of economy, even the economic collaborative degree is higher than other developed countries.

From the carbon reduction subsystem collaborative degree aspect, India and China have the highest mean value of carbon collaborative degree from 1982-2010, and followed by UK and Japan, while US and Holland have the lowest mean value. The carbon emission potential is high of India and China although the carbon degree is low. As for UK, Holland, Japan and US and such developed countries, which are proficient at carbon reduction technology, get small potential of technical emission reduction.

From the complex system collaborative degree aspect, the collaborative degree mean of economic growth and carbon reduction complex system for six countries from 1982 to 2010 are negative. Specifically, UK and Holland hold the highest complex collaborative degree as they focus on the construction of low-carbon economy a long time ago. Different from the European countries, US and Japan get the low complex collaborative degree which is caused by the economic stagnation. On the other hand, complex collaborative degree of China and India are higher than US and Japan, but lower than UK and Holland, which is because they get the weak economic foundation and lag developed countries in low carbon economy development.

\section{B. Comparison based on different stages}

It can help to find the difference in the growth stage based on the three stage analysis, which can clear the reasons for gaps and the potential of low- carbon economy development. This research divides the paper into three parts: 1982-1992, 1993-2002 and 2003-2010. Besides, author calculates the collaborative mean value of each stage, which is shown as follows: 
TABLE V. MEAN COMPARISON BETWEEN THREE STAGES

\begin{tabular}{|c|c|c|c|c|c|c|c|c|c|}
\hline & \multicolumn{3}{|c|}{ Economic collaborative degree } & \multicolumn{3}{|c|}{ Carbon collaborative degree } & \multicolumn{3}{|c|}{ Complex collaborative degree } \\
\hline & Stage 1 & Stage 2 & Stage 3 & Stage 1 & Stage 2 & Stage 3 & Stage 1 & Stage 2 & Stage 3 \\
\hline NLD & 0.0367 & 0.0194 & 0.0134 & 0.0165 & -0.0005 & 0.0121 & -0.0109 & -0.0049 & -0.0402 \\
\hline UK & 0.0336 & 0.0250 & 0.0084 & 0.0273 & 0.0274 & -0.0185 & 0.0082 & 0.0053 & -0.0788 \\
\hline US & 0.0326 & 0.0120 & 0.0111 & 0.0115 & 0.0104 & 0.0017 & -0.0709 & -0.0331 & -0.0800 \\
\hline JPN & 0.0051 & 0.0302 & 0.0271 & 0.0277 & 0.0037 & 0.0005 & -0.0210 & -0.0223 & -0.0669 \\
\hline IND & 0.0162 & 0.0250 & 0.0447 & 0.0082 & 0.0310 & 0.0297 & -0.0405 & -0.0287 & 0.0048 \\
\hline CHN & 0.0619 & -0.0023 & 0.0130 & 0.0076 & 0.0273 & 0.0182 & -0.0357 & -0.0261 & -0.0136 \\
\hline
\end{tabular}

According to the table 5, the economic collaborative degrees of three developed countries have greatly decreased from stage 1 to stage 3 expect Japan; India grows rapidly, and China shows a trend of decline after up. Besides, the carbon collaborative degrees of developed countries are generally higher than China and India in stage 1; however, the carbon collaborative degrees of China and India in stage 2 have catch up with developed countries quickly, even higher than developed countries in stage 3. In addition, collaborative degrees in China and India are significantly lower than that in Holland, UK and Japan in stage 1. US get the lowest collaborative degree as they are affected by the economic development and other factors. However, the collaborative degrees in China and India are still lower than those in developed countries with narrowing gap in stage 2 . Furthermore, the collaborative degrees in China and India are significantly higher than developed countries in stage 3.

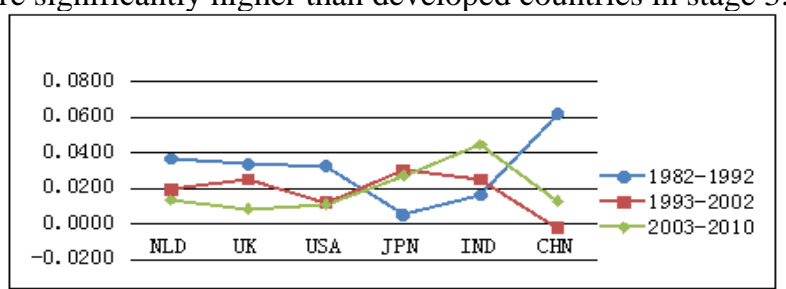

Figure .1 Economic collaborative compare in three stages

\begin{tabular}{lccccc}
\hline & \multicolumn{3}{c}{ Economic order degree } & \multicolumn{2}{c}{ Carbon order degree } \\
\hline Holland & 1992 & 2002 & 2008 & 1992 & 0.5724 \\
UK & 0.5398 & 0.7341 & 0.7743 & 0.5776 & 0.7352 \\
US & 0.5060 & 0.7557 & 0.6657 & 0.4617 & 0.7902 \\
Japan & 0.5862 & 0.7064 & 0.6329 & 0.5018 & 0.6053 \\
India & 0.3481 & 0.6503 & 0.6898 & 0.5421 & 0.5795 \\
China & 0.3898 & 0.6398 & 0.6822 & 0.3930 & 0.7029 \\
\hline
\end{tabular}

\section{V.CONCLUSIONS AND OUTLOOK}

This research makes the conclusion as follows: From the perspective of subsystem order degree, the developed countries are better than China and Indian; from the perspective of subsystem collaborative degree, China and

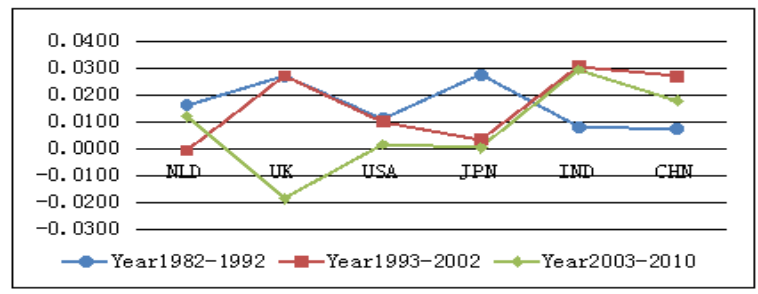

Figure 2. Carbon collaborative degree compare in three stages

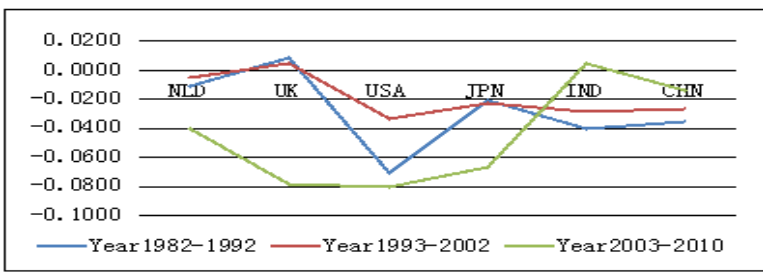

Figure 3. Complex collaborative degree compare in three stages

\section{Comparison based on key year}

This research selects year 1992, year 2002 and 2008 as the crucial years for analysis. As the collaborative degree is calculated by comparison with the previous year's value based on the time series, therefore, under the background of crucial years, it would be more convincing of order degree analysis rather than collaborative degree analysis. The order degree of relevant years is shown below:
Indian done better than developed countries; from the perspective of complex system collaborative degree, UK and the Netherlands done better than India and China, and these four countries are followed by Japan and the United States. According to the stages division research, as time passed by, 
the collaborative degree of economic growth and carbon emissions of China and India rapidly overtakes the United States, Japan, Britain and the Netherlands. With rapid economic growth, China and India have made tremendous contributions to global carbon reduction.

\section{REFERENCES}

[1] Qiao Zhen. Conflict between developing low-carbon economy and speeding economic growth?. Journal of Soochow University, (4),pp.92-97, 2012.

[2] Tu Zhengge, Strategic Measures to Reduce China’s Carbon Emissions: Based on Index Decomposition Analysis of Carbon Emissions in Eight Industries. Journal of Social Sciences in China, (3),pp.78-96, 2012.

[3] Lin Boqiang, Sun Chuangwang. How can China Achieve Its Carbon Emission Reduction Target while Sustaining Economic Growth? Journal of Social Sciences in China, (1),pp.64-77,2011.

[4] Chen Wu, Li Yun-feng. Current situation of China's low-carbon economy and energy development strategy. Journal of China Mining Magazine,19 (2),pp.4-8,2010.
[5] Chen Wu, Chang Yan. An International Comparison Study on Low-carbon Development in China: A Perspective on the Endowment of Resources. Journal of China Population, Resources and Environment,21(12),pp. 276-279,2011.

[6] Chen Wu, Chang Yan, Li Yunfeng. An International Comparison on Carbon Footprint of China. Journal of Forum on Science and Technology in China,(3),pp.138-144, 2013.

[7] Chen Wei, Zhu dajian. The Efficiency of CO2 Emissions in China is Low---A Perspective of Wellbeing for International Comparison. Journal of Research on Economics and Management, (1),pp.56-63,2011.

[8] Fu Jiafeng, Zheng Linchang. China's Low-Carbon Economic Development: An Inter-Provincial and International comparison. Journal of Resource Science, 33(4),pp.57-61,2011.

[9] Yuan Fuhua. The Potential Economic Growth of China with Restraint of Low Carbon Economy.Journal of Economic Research Journal, (8),pp.79-89,2010.

[10] Xu Guangyue, Song Deyong. An empirical Study of the Environmental Kuznets Curve for China's Emissions---Based on Provincial Panel Data, Journal of China Industrial Economics, (5),pp. 37-47, 2010. 